\title{
Modeling and analysis of responsive space launch system based on timed colored Petri $\mathrm{NeT}$
}

\author{
Qian Zhang*, and Xinhong Li \\ Astronautics Engineering University, Beijing, China
}

\begin{abstract}
Responsive space launch is currently developing rapidly and has application cases in many fields, with advantages such as fast response speed and flexible networking. Aiming at the efficiency evaluation of responsive space launch system, this article first summarizes the typical process of fast space launch, and then gives a hierarchical model of a space fast launch system based on timed colored Petri nets, including top-level model, demand model, command decision model, launch Model, measurement and control model, and finally use CPN Tools to simulate and verify the model, analyze the basic characteristics of the model and the performance of the system, and provide data support and theoretical basis for the optimization of the fast space launch system.
\end{abstract}

Keywords: Responsive space launch, Timed colored Petri Net, Efficiency evaluation.

\section{Introduction}

In recent years, with the widespread use of satellites in various fields, the responsive space launch has great demands in actual use due to their fast response speed and flexible networking. For example, in the event of a sudden disaster, the implementation of the rapid launch of small satellites in order to quickly rescue the trapped persons; in the real-time monitoring of monitoring hotspots, the implementation of the rapid launch of small satellites in order to obtain more information; in the application of space-based information, through the use of small satellites networking realizes global communication coverage and so on. The responsive space launch is evolved from the traditional space launch, through optimization in technology and process to achieve the purpose of rapid launch in a relatively short time. A lot of work is currently in progress for technical optimization, such as new launch vehicles, modular spacecraft, and multiple launch methods. However, the optimization of the process lacks corresponding research. This paper simulates the fast space launch process based on colored Petri nets, analyzes and verifies the model, and provides data support and theoretical basis for the optimization of the fast space launch system in the next step.

*Corresponding author: 347211084@qqq.com 


\section{Responsive space launch process analysis}

Responsive space launch refers to an action that enhances or supplements existing space capabilities by rapidly launching reserve spacecraft during emergencies to achieve the purpose of providing information support for users on the ground. The typical application process is as follows:

\subsection{Demand establishment}

In the event of an emergency, because users cannot use space-based information normally or lack space-based capabilities, they first need to complete the establishment of requirements, including information support types, time and location requirements, etc., and then report the requirements to the command center.

\subsection{Command decision}

When the command center received the user's demand information, it immediately studied and judged the situation and determined that the information support could not be used to complete the mission by maneuvering the satellite in orbit. It must be launched quickly to meet the demand. Then conduct a feasibility analysis of the mission, establish the launch time, location, method, and urgency, convert the mission data into launch commands, and divide the mission into three levels by judging the urgency of the mission. Finally, the launch command is passed to the launch unit.

\subsection{Implement launch}

After the launch unit receives the launch command, it plans the mission according to the launch time, location, method and other information, and executes different mission processes according to the level of the mission. When the mission level is 1 , directly use the assembled and tested reserve satellites and launch vehicles to perform rocket launch tasks; when the mission level is 2 , follow the procedures to test, dock and launch the assembled reserve satellites and launch vehicles; when the mission level is 3, the satellites and launch vehicles required by the mission are assembled, tested, docked and launched. After the mission is completed, the satellite launch completion status is passed to the measurement and control unit.

\subsection{On-orbit measurement and control}

The measurement and control unit quickly organizes on-orbit measurement and control of the satellite after receiving the completion status of the satellite launch. When the satellite is in good working condition, the space-based information is delivered to the user or the user can obtain the space-based information by himself. When the satellite works abnormally, re-plan the mission.

\section{CPN model of fast space launch system}

Modeling is carried out according to the responsive space launch process. The CPN model of the responsive space launch system includes a top-level model, a demand establishment model, a command decision model, a launch model, and an on-orbit measurement and control model. The detailed model information is as follows. 


\subsection{Top-level model}

In Fig.1, the top-level model of the responsive space launch system includes four main subpages: demand, command decision, launch, and measurement control, as well as the information and resource exchange process between them. It mainly describes the overall process, information and resource flow of the fast space launch system, and describes the entire process of a typical mission.

\subsection{Demand model}

In Fig.2, the demand subpage model of the responsive space launch system describes the process of requirement establishment. Assuming that the probability of emergencies obeys the Poisson distribution, after the incident, the user confirms the demand for space-based information, then reports the demand to the command center, and the reporting time obeys the normal distribution, and finally generates demand information for subsequent processing.

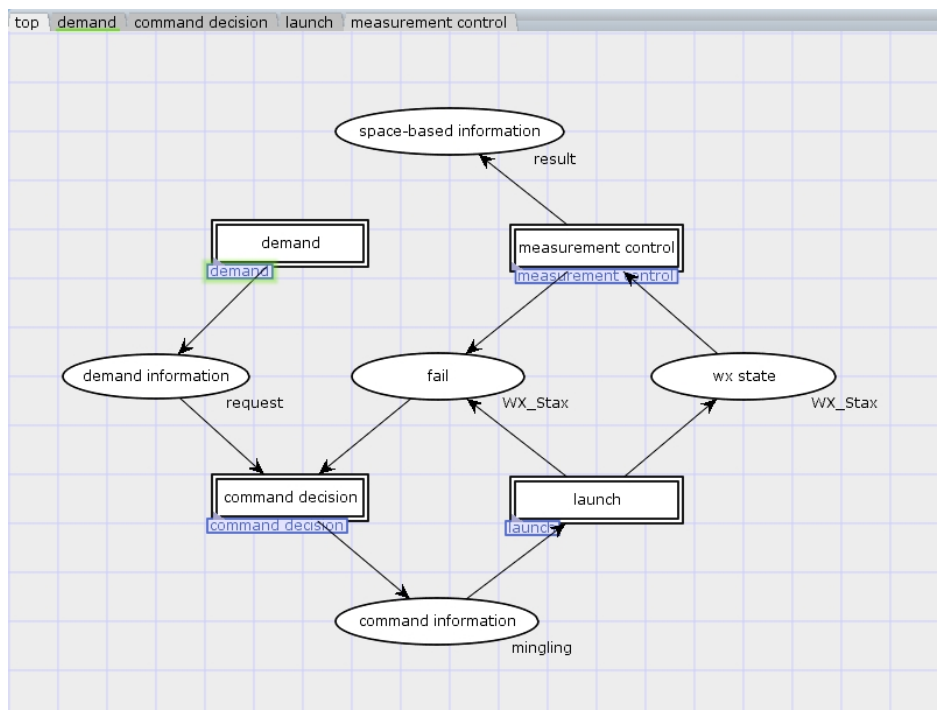

Fig. 1. Fast space launch system model(top).

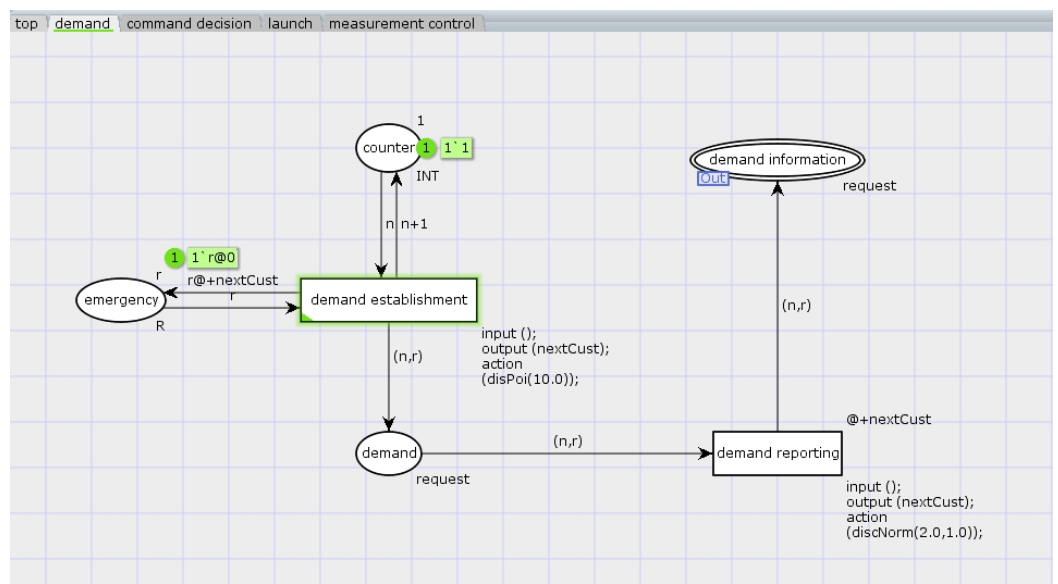

Fig. 2. Fast space launch system model(demand). 


\subsection{Command decision model}

In Fig.3, the command decision subpage model of the responsive space launch system describes the command decision process. After the demand information is entered, the situation research and judgment are carried out first, and the research and judgment time obeys the normal distribution, and then the feasibility analysis is carried out. The analysis time obeys the normal distribution, and the task data can be obtained, and then the task level is determined according to the task data. Finally get the command information. When there is a problem with task execution, the task data will re-enter the queuing sequence.

\subsection{Launch model}

In Fig.4, the launch subpage model of the responsive space launch system describes the launch process. After the command information is entered, the task planning is carried out, and the planning time obeys the normal distribution; then according to the task level, enter the first-level task, the second-level task, and the third-level task, respectively, perform module manufacturing, test inspection, and rocket launch until the launch is completed; Assuming that the launch has a $98 \%$ probability of working normally, the launch completion status will be provided to the on-orbit measurement and control, otherwise it will re-enter the waiting decision sequence.

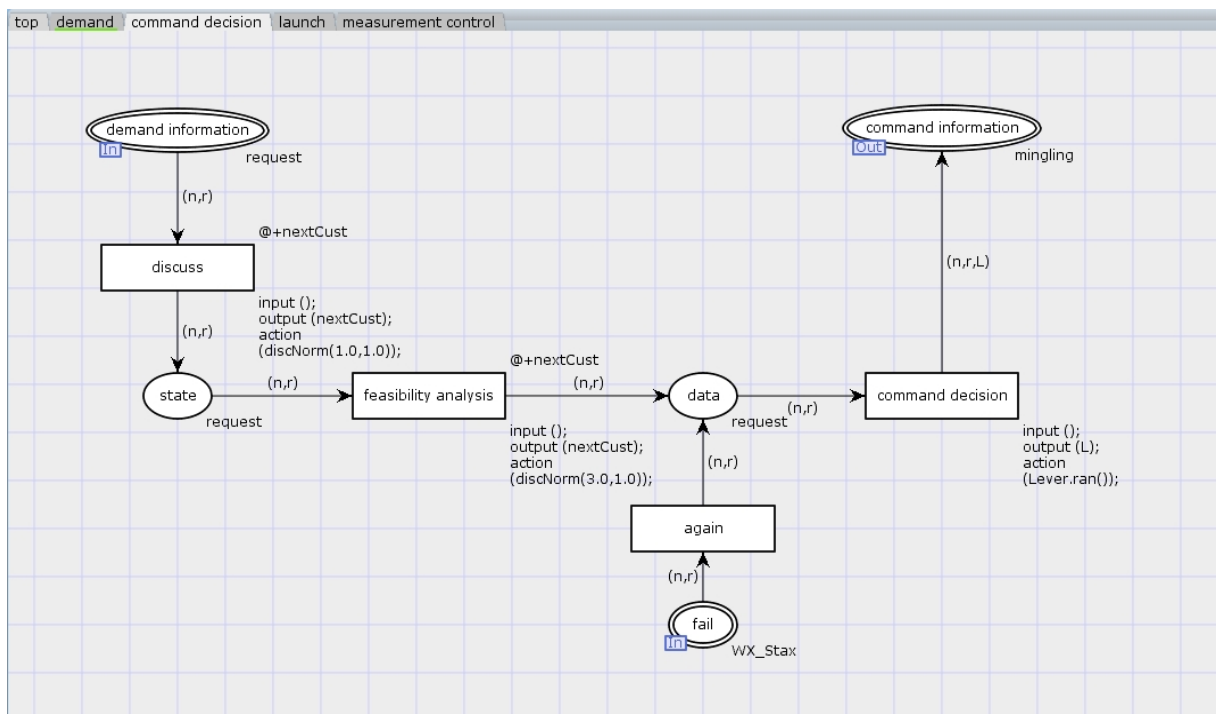

Fig. 3. Fast space launch system model(command decision). 


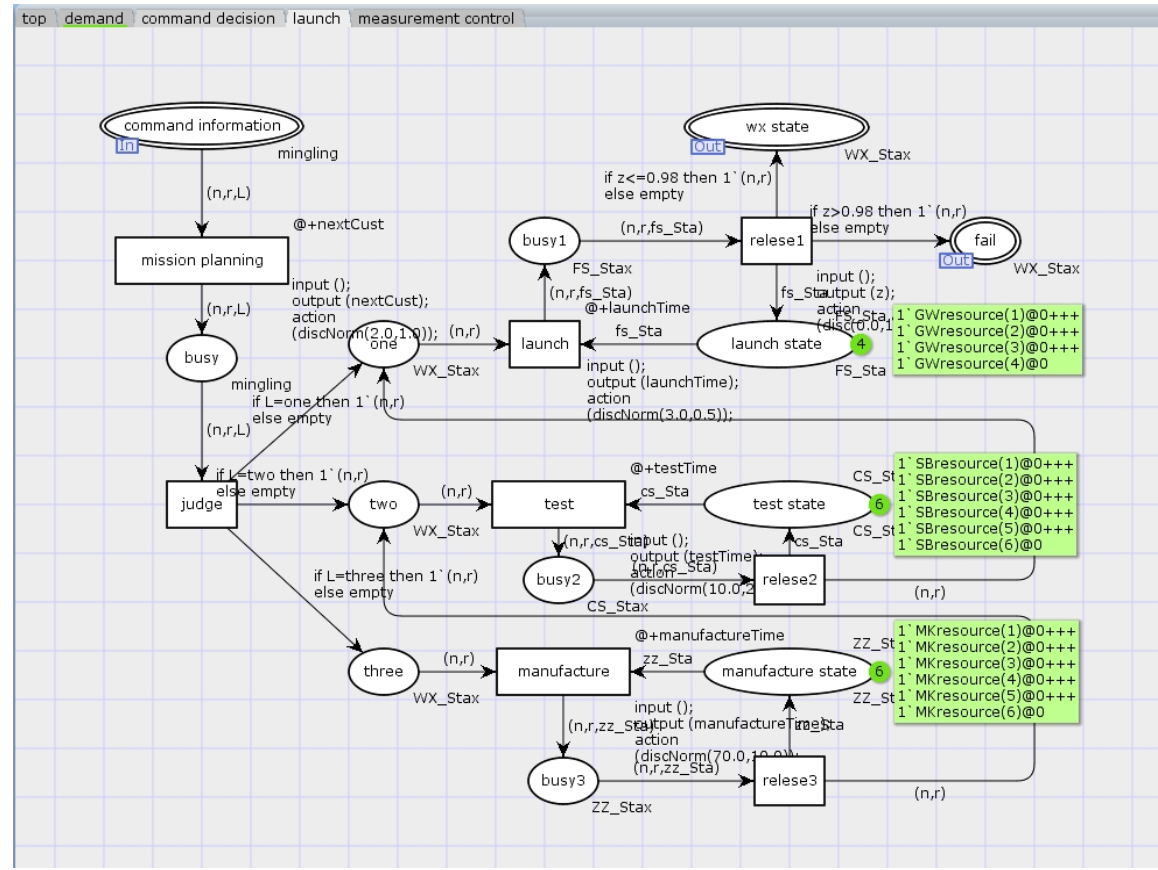

Fig. 4. Fast space launch system model(launch).

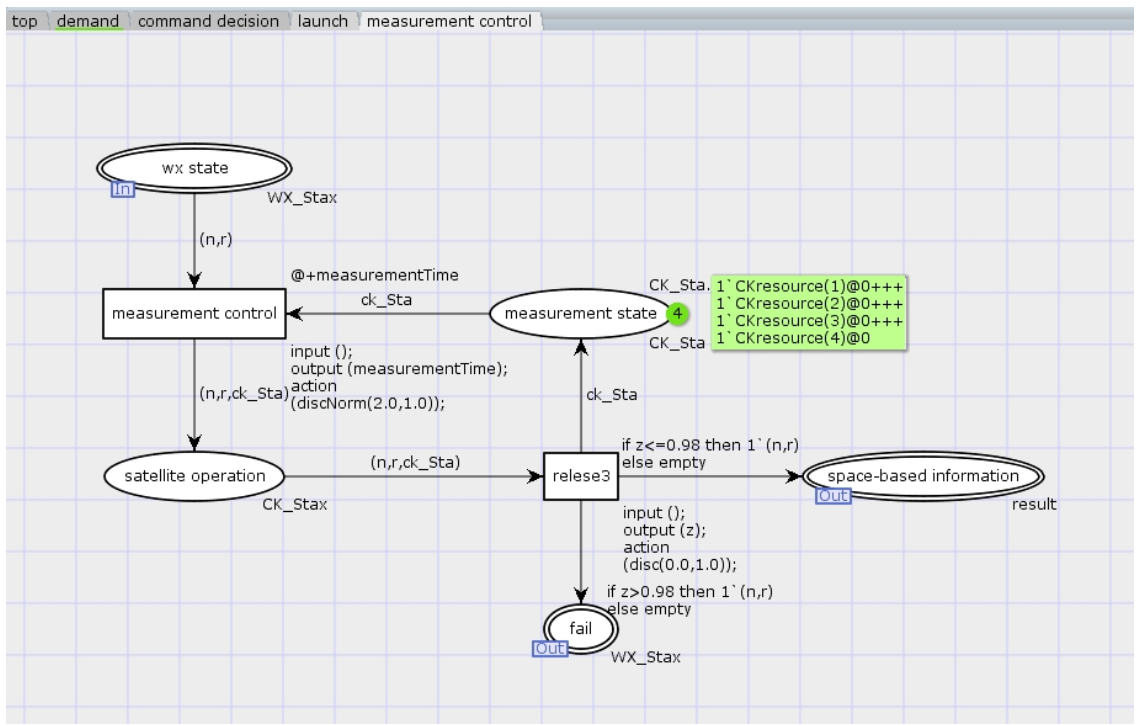

Fig. 5. Fast space launch system model(measurement control).

\subsection{Measurement control model}

In Fig.5, the measurement control subpage model of the responsive space launch system describes the process of on-orbit measurement and control. After receiving the launch completion status, the satellite will be monitored and controlled in orbit, and the satellite working status report will be generated; assuming that the satellite has a $98 \%$ probability of 
working normally, it can provide the user with space-based information, otherwise it will re-enter the waiting decision sequence.

\section{Simulation and analysis of CPN model for fast space launch}

Use CPN Tools to simulate and analyze the established model. Through dynamic behavior verification, it is determined that the model can express the working process of the responsive space launch system, and then the accessibility, boundedness, and activity of the system are analyzed according to the state space report.

\section{Statistics \\ State Space \\ Nodes: 103758 \\ Arcs: 120701 \\ Secs: 300 \\ Status: Partial \\ Scc Graph \\ Nodes: 103758 \\ Arcs: 120701 \\ Secs: 2}

Fig. 6. State space report (Statistics).

\begin{tabular}{|c|c|c|c|}
\hline \multicolumn{4}{|l|}{ Boundedness Properties } \\
\hline \multicolumn{4}{|l|}{ Best Integer Bounds } \\
\hline \multicolumn{4}{|l|}{ Upper } \\
\hline \multicolumn{4}{|c|}{$\begin{array}{l}\text { command_decision'data } 12 \\
\text { command_decision'state } 1\end{array}$} \\
\hline-3 & & 0 & \\
\hline demand'counter 1 & & 1 & 1 \\
\hline demand'demand 1 & & 8 & 0 \\
\hline demand'emergency & & 1 & 1 \\
\hline launch'busy 1 & 1 & 0 & \\
\hline launch'busy1 1 & 1 & 0 & \\
\hline launch'busy2 1 & 1 & 0 & \\
\hline launch'busy3 1 & 1 & 0 & \\
\hline $\begin{array}{l}\text { launch'launch_state } \\
\text { launch'manufacture }\end{array}$ & & & 3 \\
\hline 6 & & 5 & \\
\hline launch'one 1 & 1 & 0 & \\
\hline launch'test_state 1 & 6 & 5 & \\
\hline launch'three 1 & 1 & 0 & \\
\hline $1-\ldots-1-1+\ldots-1$ & $i$ & n & \\
\hline
\end{tabular}

Fig. 7. State space report

(Boundedness Properties).

Home Properties

Home Markings

Initial Marking is not a home marking

Fig. 8. State space report(Home Properties),

Liveness Properties

Dead Markings
$94484[99999,99998,99997,99996,99995, \ldots]$
Dead Transition Instances
$\quad$ None
Live Transition Instances
None

Fig. 9. State space report(Liveness Properties). 
Fairness Properties

No infinite occurrence sequences.

Fig. 10. State space report(Fairness Properties).

The status analysis report is shown in the figure, and the system characteristics are good. The system model has 103758 nodes and 120701 arcs, and all nodes and arcs are reachable; all the places meet the requirements of bounds, and there is no accumulation of tokens in the places, the system model is bounded; the initial marking is not a home marking; all changes in the model are stimulated during the operation, and there is a fixed end; the model does not occur in an infinite automatic loop, which meets the fairness requirements.

\section{Conclusion}

Mainly research the modeling and simulation of fast space launch process. Based on colored Petri nets to model the rapid space launch, the model has certain versatility and feasibility. Use CPN Tools to simulate the model to verify the basic characteristics of the model, such as boundedness, reachability, and fairness. The simulation model can be used to evaluate the effectiveness of fast space launches, which has certain reference significance.

\section{References}

1. Li Gang, HAN Longmei, ZHU yongli. Trusted Modeling and Analysis of Complex Software Systems Based on Spatial-temporal Petri Nets[J]. Journal of System Simulation, 2016,28(8):1740-1747.

2. K Jensen. Colored Petri Nets: Basic Concepts Analysis Methods and Practice Use[M]. New York:Free Press,1992:39-49.

3. Hee K V, Oanea O, Sidorova N.Colored Petri Nets to Verify Extended Event-Driven Process Chains[J]. Lecture Notes in Computer Science, 2015, 3760:183-201.

4. Julia Padberg,Kathrin Hoffmann. A Survey of Control Structures for Reconfigurable Petri Nets[J]. Journal of Computer and Communications,2015,03(2):20-28.

5. Yu W, Jia M, Fang X, et al. Modeling and analysis of medical resource allocation based on Timed Colored Petri net[J]. Future Generation Computer Systems, 2020, 111.

6. Wang Rui et al. Automated test case generation for the Paxos single-decree protocol using a Coloured Petri Net model[J]. Journal of Logical and Algebraic Methods in Programming, 2019, $104:$ 254-273.

7. Bhandari Guru Prasad. Dependency-based fault diagnosis approach for SOA-based systems using Colored Petri Nets[J]. Journal of King Saud University - Computer and Information Sciences, 2018.

8. Sanjib Kumar Saren and Florin Blaga and Tiberiu Vesselenyi. Automated production based model of flexible cell using Timed Colored Petri Nets[J]. MATEC Web of Conferences, 2017, 126. 